\title{
Elbow Ulnar Collateral Ligament Reconstruction Using the Novel Docking Plus Technique in 324 Athletes
}

\author{
Benjamin F. Donohue ${ }^{1}$, Marc G. Lubitz $2^{2^{*}}$ and Timothy E. Kremchek ${ }^{3}$
}

\begin{abstract}
Background: This retrospective case series examined 324 athletes who received elbow ulnar collateral ligament (UCL) reconstruction by a single surgeon in a private practice over a 9-year period. The novel Docking Plus technique for elbow UCL reconstruction in 324 athletes provided good or excellent Conway score results in $88 \%$ of patients. The preponderance of previous studies examining UCL reconstruction outcomes were performed by surgeons at one of only three institutions (Andrews Institute, Hospital for Special Surgery, Kerlan Jobe Orthopedic Clinic).

Methods: Patients undergoing UCL reconstruction from November 2005 to December 2014 were identified and contacted with a mailed survey and phone call. These patients were given a subjective 19 question survey assessing their outcomes from surgery.

Results: The participants who responded to our survey were $90 \%$ male and $77 \%$ baseball players, $73 \%$ of which were pitchers. Of the baseball players who responded, 51.9\% were in high school at the time of their surgery, $37 \%$ college, $6.5 \%$ minor leagues, and 2.2\% in Major League Baseball. After surgery, 36\% of survey responders returned to a higher level of competition than previously. For example, a high school athlete who had UCL reconstruction and went on to pitch in college. Further, 45\% returned to the same level, and 7\% returned to a lower level. Subjective "satisfaction," was reported in 92\% of responders and 97.2\% reported that, "having surgery was a good idea." Symptom onset in the responding athletes was $58.9 \%$ sudden, and $41.1 \%$ gradual. Overall, $90.9 \%$ of respondents returned to play in less than 1.5 years while $6.3 \%$ never were able to return. Re-tear occurred in $2.5 \%$ of patients, while $8.8 \%$ had subjective nerve dysfunction for at least 3 months following surgery.
\end{abstract}

Conclusion: The Docking Plus technique can produce excellent subjective and objective results in athletes. Further study is warranted to see the effects of this procedure in other settings and determine which method of reconstruction or repair is superior.

Keywords: UCL, Elbow, Baseball, Tommy John Surgery, Ligament reconstruction

\section{Key Points}

- The majority of UCL reconstruction outcomes studies are from just three major institutions

- Eighty-eight percent of survey respondents who completed their rehab protocols following UCL reconstruction with the Docking Plus technique had a Conway-Jobe score of good or excellent

\footnotetext{
* Correspondence: MarcLubitz@gmail.com

2UMass Medical School, 55 Lake Ave N, Worcester, MA 01655, USA

Full list of author information is available at the end of the article
}

- More studies examining objective outcomes following UCL reconstruction are needed

\section{Background}

Injury to the elbow ulnar collateral ligament (UCL) and its surgical reconstruction in throwing athletes is well described $[2,4,5,7,8,10-26,29,32-36,41,43,47,60$, $64,74]$. The incidence of UCL reconstruction surgery is increasing, among high school athletes and professional athletes $[6,17,35,46,77,79]$.

The UCL is the primary valgus stabilizer of the elbow. It experiences the most torque in the late cocking and 
early acceleration phases of the pitching motion kinetic chain $[38,40,41,58,59,75]$. Pitching velocity and volume have both been associated with an increased risk of UCL injury [3, 14, 28, 31, 39, 52, 61, 62, 67, 78].

Patients often, though not always, complain of acute or chronic medial elbow pain when throwing, which affects velocity and accuracy. Physical exam generally reveals pain with elbow valgus stress testing and palpation of the UCL [45]. MRI with intra-articular contrast and dynamic ultrasound have the highest sensitivity in diagnosis of UCL injuries [20, 37, 71, 76]. Reconstructive surgery is typically recommended for full-thickness tears as well as partial thickness tears refractory to non-operative management. Internal bracing for partial tears has recently emerged as a possible alternative to full reconstruction [30].

Since the year 2000, published case series of surgical outcomes for UCL reconstruction have demonstrated rates of return-to-play (RTP) of $74-100 \%[4,10,13,19$, 21, 22, 24, 29, 49, 50, 63, 66, 69, 72]. Studies of Major League Baseball (MLB) pitchers have shown RTP rates of $67-87 \%[34,44,50,53,56]$.

A variety of surgical techniques have been described, including the Docking Plus technique [57]. Though UCL reconstruction patient outcomes have been measured in multiple level 3 and 4 studies, these studies have typically had low numbers $(<100)$ of patients. Also, the preponderance of the included surgeries were performed by surgeons at one of only three institutions (Andrews Institute, Hospital for Special Surgery, Kerlan Jobe Orthopedic Clinic). The purpose of this paper is to provide data from previously unreported outcomes of 324 athletes at a single surgeon center who underwent UCL reconstruction using the "Docking Plus," technique.

\section{Methods}

We identified all UCL reconstructions performed by the senior author (TEK) from November 2005 to December 2014. We did so by searching the senior surgeon's practice patient database by surgeon and Current Procedural Terminology (CPT) code (24346). CPT code 24346 is defined as, "Reconstruction medial collateral ligament, elbow, with tendon graft (includes harvesting of graft)". This yielded 655 results of 647 unique patients. These reconstructions were all done with the docking plus technique and utilized the contralateral palmaris longus tendon for the graft when present. If the patient did not have palmaris longus tendons, a gracilis tendon autograft was used.

A literature search was conducted to compare our study's outcomes to previously reported data. We searched PubMed and Google Scholar for UCL reconstruction outcome studies and found 25 such studies published between 1986 and 2014 [4, 8, 10, 13, 19, 21, 22, 25, 29, $34,44,48-51,53,55,56,63,65,66,69,70,72]$. Of these studies, $19[4,8,10,13,19,21,22,25,29,49,51,54$, $55,63,65,66,69,70,72]$ detailed outcomes by surgeon authors, while 6 studies [34, 44, 48, 50,53,56] reported outcomes with data from MLB databases.

For each study, we charted the outcomes and patient and injury characteristics measured. All of the 19 case series measured the competition level of return-to-play with 12 of these studies explicitly using Conway-Jobe or modified Conway-Jobe criteria in their classifications. Several other outcome metrics were used in these case series, including the Andrews-Timmerman elbow score (3 of 19 studies) $[22,51,55]$, the KJOC (Kerlan Jobe Orthopedic Clinic) Score (1 of 19) [51], DASH (Disabilities of the Arm, Shoulder, \& Hand) score (1 of 19) [63], and MEPI (Mayo Elbow Performance Index) score (1 of 19) [54].

A 2-page, 19-question survey was designed with questions about demographics (e.g., age, gender), sports participation (e.g., sport, position, handedness), the nature of the injury (e.g., speed of onset, timing, prior surgery), subjective outcomes (e.g., patient satisfaction), and objective outcomes (e.g., timing and level of return-to-play, ConwayJobe score, career longevity, reasons for retirement, complications).

We used contact information (mailing address, telephone number) provided by patients at the time of prior clinical encounters to contact the patients. We mailed letters containing a URL link to the survey and a unique, anonymized patient identification number. In addition to standard mail, we contacted patients by telephone to provide them with the survey URL, their identification numbers, and to briefly describe the purpose of the outcomes study. We obtained an advisory opinion which states that our survey posed minimal risk and met criteria for being IRB exempt.

\section{Surgical Technique}

The Docking Plus technique for UCL reconstruction (Figs. 1 and 2) was utilized. The patient is positioned supine with the operative extremity on a hand table. They are prepped and draped in sterile fashion. The elbow is flexed to $30^{\circ}$ and a curved incision is made just posterior to the medial epicondyle. Care is taken to avoid the medial antebrachial cutaneous nerve during dissection, and the ulnar nerve is visualized to allow protection during retraction. The nerve is not routinely transposed. The flexor mass is split and the native UCL is identified. The UCL is then incised and peeled back. A $2.7-\mathrm{mm}$ drill is used to make two unicortical drill holes, one anterior and one posterior to the sublime tubercle. The holes are curetted until they converge and a passing suture is passed through. A unicortical socket near the humeral anatomic origin of the UCL is made with a 4-mm burr. A $2.7-\mathrm{mm}$ drill is used to make two unicortical holes on the posterior medial epicondyle. A 
A

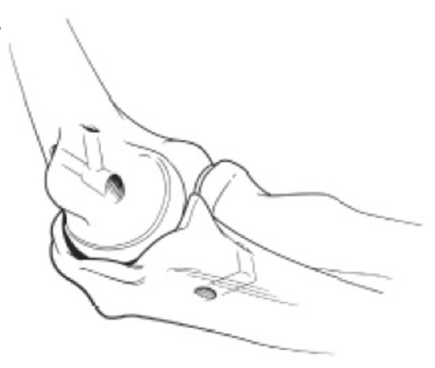

C

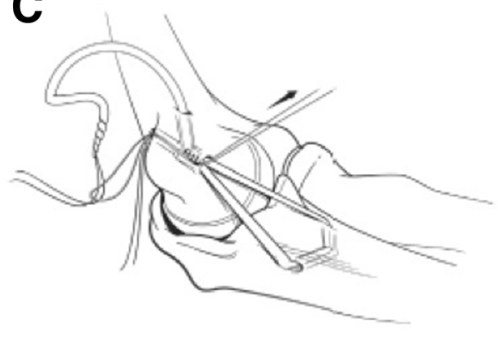

E

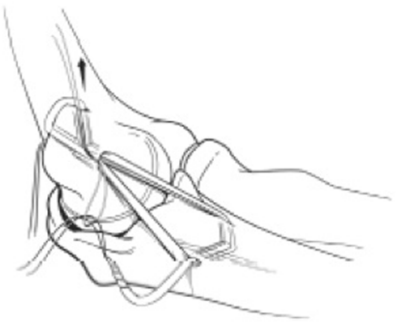

B

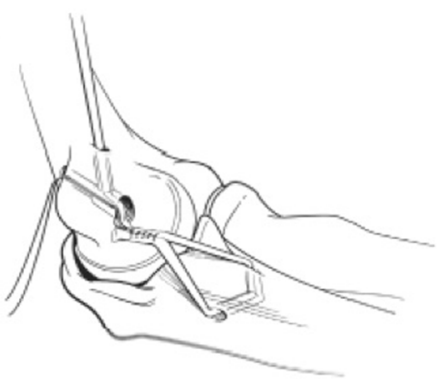

D

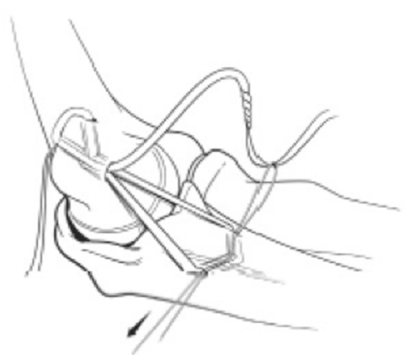

F

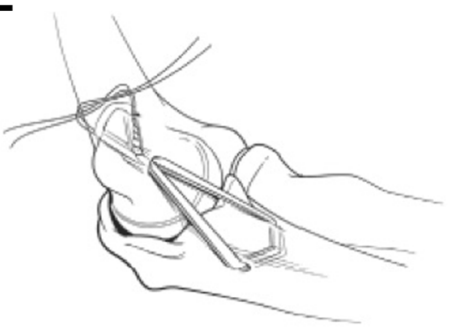

Fig. 1 The Docking Plus Technique. a The bone tunnel locations within the proximal ulna and medial epicondyle of the humerus. b The graft is first passed through the ulnar tunnel, and the short end of the graft is sutured in a Krackow fashion; then, the suture ends are brought out the posterior exit holes of the medial epicondyle, while the graft is taken through the anterior exit holes. c The long end of the graft is then passed through the posterior medial epicondyle tunnel as the sutures are held at constant tension. $\mathbf{d}$ The graft is passed once again through the ulnar bone tunnels. e For the final pass, the graft is taken through the longitudinal tunnel of the medial epicondyle and out the anterior exit hole opposite the tensioned short end of the graft. $\mathbf{f}$ Both ends of the graft were then tensioned and tied together as the arm was held in a reduced position with no valgus stress at approximately $30^{\circ}$ of flexion and the forearm in neutral rotation. (McGraw et al. 2013)

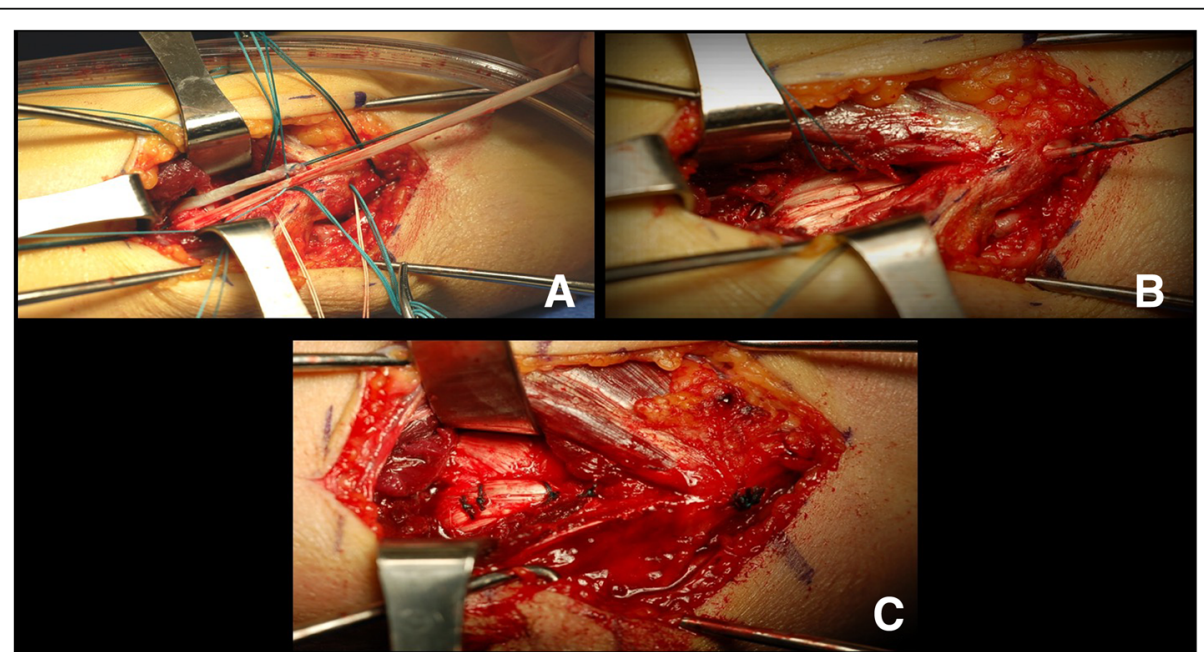

Fig. 2 Intraoperative photos. a Krakow stitch placement between short and long limbs, $\mathbf{b}$ tensioning of the 4-strand graft, and $\mathbf{c}$ figure-4 stitches placed between the 4-strands of the reconstruction and the remnant native UCL ligament 
curette is then used to connect these tunnels to the socket and suture is passed between the socket and one of the holes in the medial epicondyle. The graft is then passed through the two holes in the ulna. The short arm of the graft, the docking end, is aligned with the long arm of the graft and they are sutured together. The long arm is then passed out the lateral medial epicondyle tunnel, then the medial tunnel, across the ulnohumeral joint, through the ulnar holes, and back across the ulnohumeral joint and out the lateral hole in the epicondyle. The graft is tensioned as the arm is flexed and extended. The elbow is flexed to $70^{\circ}$ in neutral rotation and the sutured from the graft is tied. The four graft strands which cross the ulnohumeral joint are sutured together. The wound is then closed. This technique uses longer strands of autograft when compared to more commonly used techniques like the Standard Docking. This allows for two extra passes of the graft over the medial epicondyle and more graft to bone surface area for healing. Palmaris longus or contralateral gracilis tendons were used for autograft.

Postoperative rehabilitation utilized standard timelines of immobilization, strengthening, throwing programs, and return-to-play $[9,42,68]$. In weeks $1-2$, evaluation of ulnar nerve function is critical. This is monitored closely by the physical therapist and the surgeon is made aware of any possible deficit. The elbow is passively ranged from 30 to $90^{\circ}$, which can be increased if tolerated. Extension is dependent and posterior pinching. Active range of motion (AROM) at the wrist is encouraged and exercises involving grip and hand strength are performed. Cryotherapy and electrical stimulation are also utilized around the elbow. The patients brace is left locked at $60^{\circ}$. Sutures are removed at 10-14 days. At 3 weeks, the brace is set at $30-90^{\circ}$ following approval by the surgeon. Isometric wrist and forearm exercises are begun. Elbow flexion and extension isometrics are started. AROM advanced to $20-105^{\circ}$ if tolerating. At week 4 , the brace is set at $15-$ $105^{\circ}$ and they are passively ranged from 10 to 120 . Hand intrinsic muscle therapy is progressed and cardiovascular conditioning on a stationary bike is started. In weeks 5-6, the brace is fully opened and taken off by the end of week 6. Passive range of motion (PROM) is increased to 0$130^{\circ}$. Wrist and elbow resistance exercises with $1 \mathrm{lb}$ of weight are begun. A shoulder strengthening program is started.

\section{Results}

Of the 647 patients who received a survey, 3 were excluded because they did not undergo UCL reconstruction and 2 because they underwent revision UCL reconstruction. We received 335 responses to the survey, although 9 were found to be duplicate responses, 1 patient failed to respond with either his survey ID number or name, and 1 patient responded with a nonsense ID number. Therefore, we analyzed 324 responses for a $50.1 \%$ response rate. These patients had all undergone UCL reconstruction using the "Docking Plus" technique.

Survey responders were $90 \%$ (290 of 324) male, while $10 \%$ (34 of 324) were female.

Baseball was the primary sport for $77 \%$ (248) of responders. Other primary sports included softball (13), football (14), wrestling (9), volleyball (6), gymnastics (5), golf (5), cheerleading (4), tennis (4), lacrosse (4), rugby (1), and track and field (1).

Of the baseball players, $73 \%$ were pitchers, $9 \%$ catchers, $12 \%$ infielders, and 7\% outfielders (Fig. 3).

Prior to surgery, the level of performance for all athletes was middle school (2.5\%), high school (51.9\%), college $(37.0 \%)$, minor league (6.5\%), and major league (2.2\%). After surgery, the highest level of performance reached was middle school (1.9\%), high school (27.2\%), college (54.9\%), minor league (14.2\%), or major league (1.9\%).

When asked explicitly about the level of return-to-play postoperative compared with preoperatively, 36\% (104) had returned to a higher level of competition for at least one season, 45\% (130) had returned to the same level, and $7 \%$ (20) had returned to a lower level. Thus, $81 \%$ had a Conway-Jobe score of excellent, and $88 \%$ had a score of excellent or good. Note that only $88.3 \%$ (286) of all respondents had completed their rehabilitation regiment and so were eligible to answer this question (Figs. 4 and 5).

Subjectively, 92.9\% (301 of 324) were satisfied with their surgery and $97.2 \%$ (315 of 324) thought that it was a good decision to have the surgery (Fig. 6).

While patients described pre-op symptom duration and non-operative management for as little as $0-3$ months and as long as greater than 2 years, $43.3 \%$ (138) had symptoms for $0-3$ months and $68.1 \%$ (194) underwent physical therapy for $0-3$ months.

Symptom onset was sudden in 58.9\% (188), but insidious/ gradual in $41.1 \%$ (131). Of baseball pitchers, the symptom onset was sudden in 50.5\% (93), but insidious in 49.5\% (91). Then, $7.2 \%$ (23) had undergone prior surgery on the same elbow.

RTP timing varied from less than 9 months to over 2 years. Further, $90.9 \%$ (259) returned in less than 1.5 years, while $2.5 \%$ (7) returned in $1.5-2$ years, $0.4 \%$ (1) returned in over 2 years, and 6.3\% (18) did not return to play. Among pitchers, self-reported return-to-play was similar, with less than 9 months $(7 \%, 11), 9-12$ months $(48 \%, 75), 1-1.5$ years $(33 \%, 52), 1.5-2$ years $(3 \%, 5),>2$ years $(1 \%, 1)$, and never $(8 \%, 13)$.

Complications included UCL re-tear in 2.5\% (8) and additional same-side elbow surgery for any reason in 5.6\% (18). Then, 8.8\% (28) described some element of nerve dysfunction for at least 3 months postoperatively, although the survey did not distinguish between transient or permanent incision site numbness and ulnar nerve dyesthesia. 


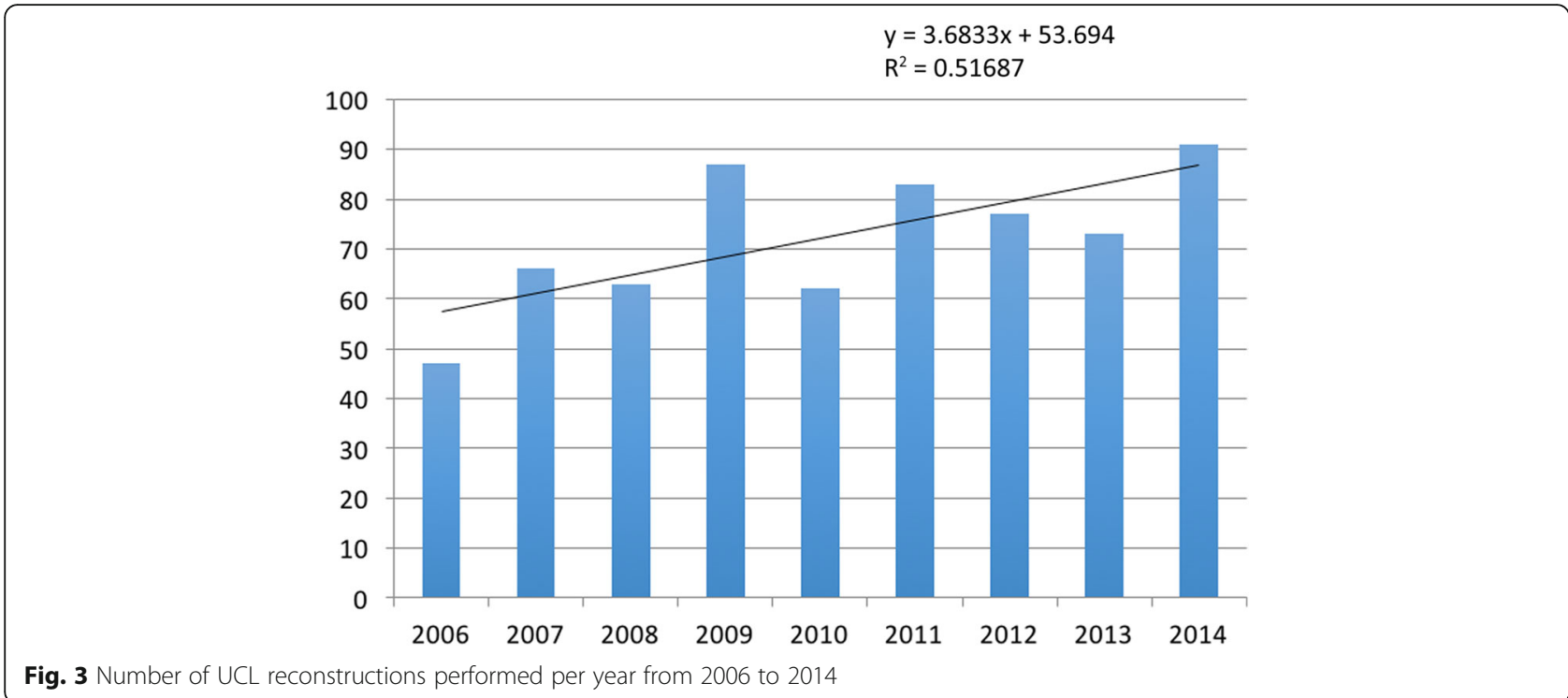

In baseball pitchers, there was self-reported subjective improvement in pitch velocity, control, ERA, and innings pitched as compared with pre-injury. Of the 155 who have by now discontinued playing their sport, only $14.8 \%$ (23) state that retirement was caused by elbow disability.

\section{Discussion}

There are many UCL reconstruction outcome studies in published literature. However, most are produced by the same few pioneering institutions, such as the Andrews Institute [4, 13, 29, 63, 66, 69], Hospital for Special Surgery [10, 22, 24, 50, 69], and Kerlan Jobe Orthopedic Clinic $[19,21,49,72]$. This raises questions as to whether or not the results can be extrapolated to other centers. This study was also performed at only one center by one surgeon, raising similar questions. However, any addition to the pool of data regarding UCL reconstruction outcomes can help the community direct future

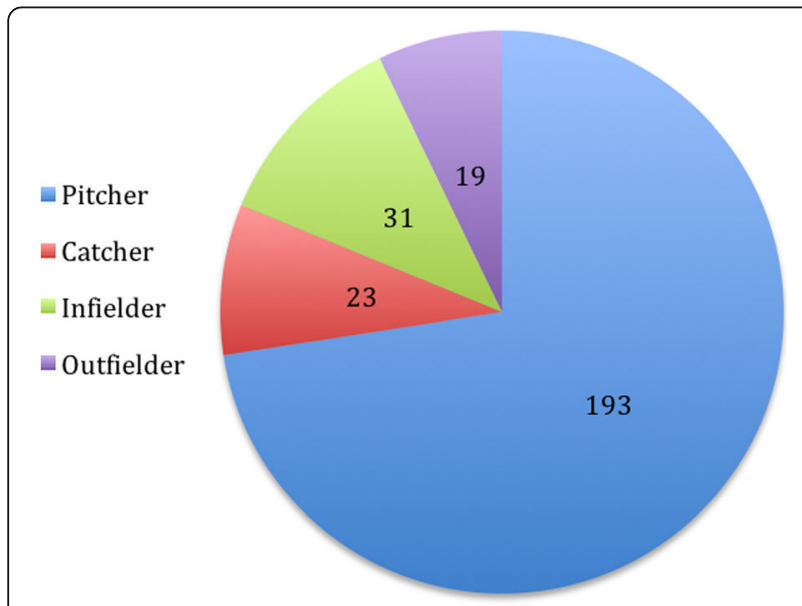

Fig. $4 \cup C L$ reconstruction patients by position goals and studies. This study also likely represents the largest case series of women (34 athletes) who have undergone UCL reconstruction. It is the only case series published on patients who have had UCL reconstruction with the "Docking Plus" technique.

Despite the increasing incidence of UCL reconstruction surgery (Fig. 7), only several outcome studies have contained more than 100 patients [10, 29, 63, 70], almost all of those on the patients of Dr. James Andrews [10, 29, 63], limiting the applicability of the results.

The Docking Plus technique, a variation on previously described Modified Docking techniques, has been previously described [27] and tested biomechanically [16], though outcome studies have not yet validated its use.

The goal of this study was to assess the performance of the Docking Plus technique of UCL reconstruction done by a single surgeon outside of the aforementioned pioneering institutions in a high volume patient series. The combined Conway score of good or excellent results of $88 \%$ is consistent with the results of similar outcome studies (Table 1).

Subjective patient satisfaction scores in this study indicate that almost $96 \%$ patients think that it was a good decision for them to have surgery. Nearly as many, $92.9 \%$, were satisfied with their surgery. This compares very favorably to patient satisfaction information from a study by Conte et al. in 2015 that found that only $72 \%$ of professional baseball players would have the surgery again and $17 \%$ would not have the surgery [24].

Our data regarding symptom onset (59\% acute, $41 \%$ gradual) varies from those results previously published in the literature that are closer to a 1:1 incidence of these two presentations [34]. Though, in baseball pitchers, our symptom onset ( $51 \%$ acute, $49 \%$ gradual) was consistent 


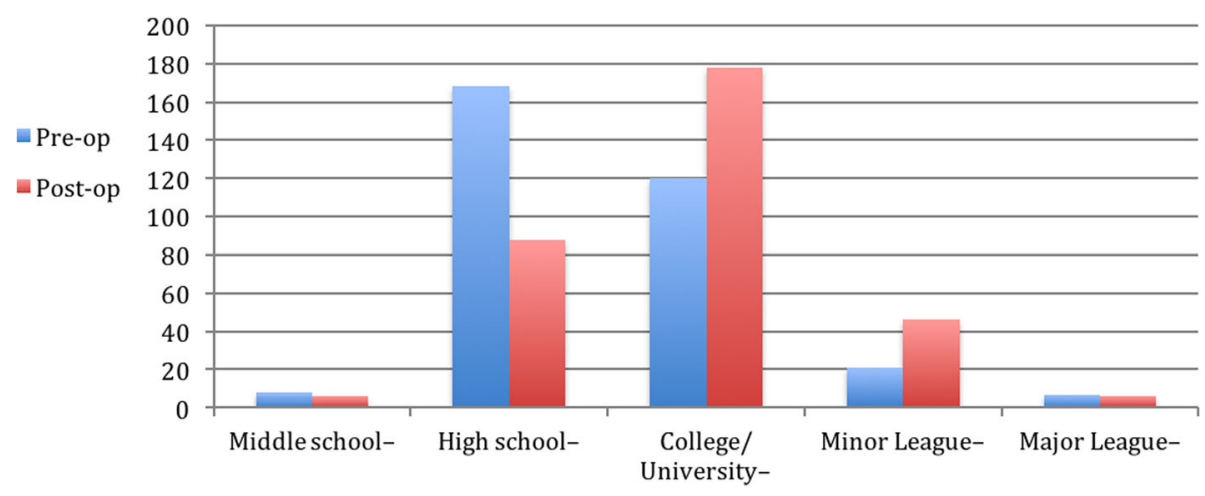

Fig. 5 Level of sports competition

with the reported incidences. Even when the presentation is described as "acute" or "traumatic" in throwing athletes, it is likely that there have been some underlying chronic degenerative changes to the UCL.

Time to return-to-play varies based on position and sport. There has been debate about delaying further professional pitchers timing of return-to-play based on some trends in improved pitching in the second year compared with in the first year after return-to-play [69, 72].

The rehabilitation protocol for pitchers dictates a returnto-play at 11-14 months if there are no setbacks. Eightyone percent of these studies pitchers returned to pitch at $9-18$ months postoperative. This is consistent with surgeon outcome studies that have shown a 11-13 month average return-to-pitch timing $[10,14,15,73]$.

Outcome studies that have utilized information from MLB databases have shown a mean return-to-play timing of 16-20 months [1, 69, 72, 78]. However, analysis of MLB data by a journalist have demonstrated that median return-to-play times in this population since 2002 have been consistently 13 months [79]. It seems that a few extended and complicated postoperative courses in MLB pitchers have skewed up the means reported in academic studies. Return-to-play is faster for baseball position players and non-baseball players.

\section{Limitations}

The data in this study was self-reported and so is vulnerable to recall bias. Electronic medical records were accessed for the date of surgery and CPT code, but not for details of the patients' histories and physical exams.

Return to sport can be affected by a variety of social and medical factors unrelated to the technical success of the surgical procedure including continued interest in sport, skill level, and commitment to a lengthy rehabilitation process. As much as the senior surgeon's patient selection includes operating on patients who have the

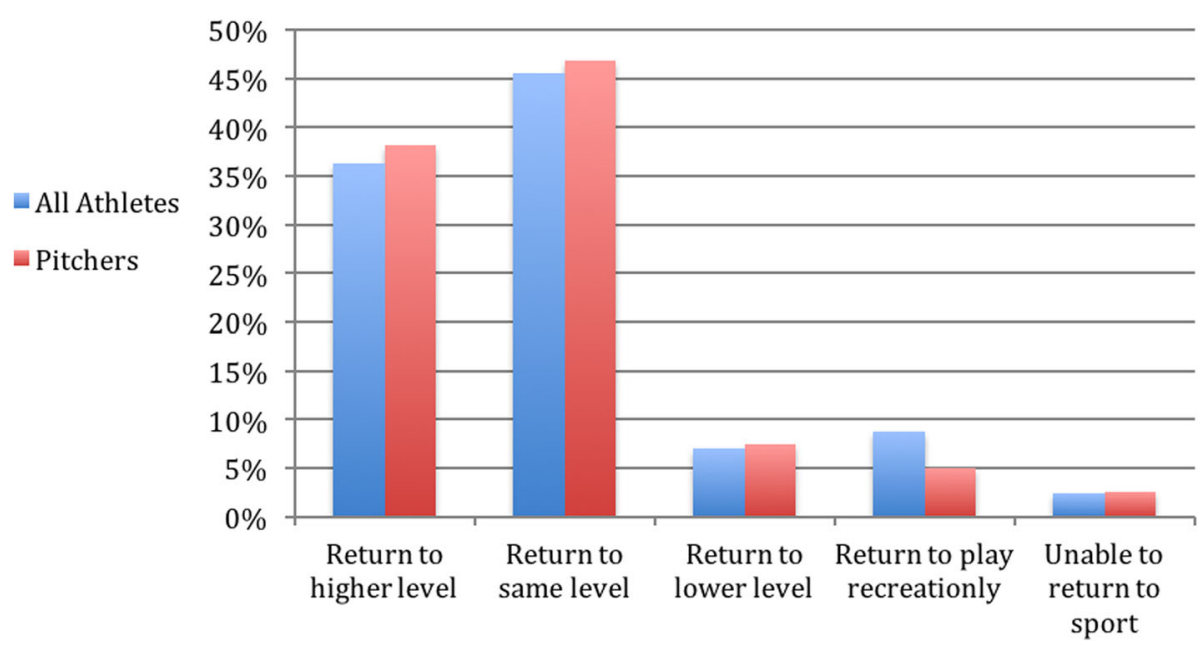

Fig. 6 Level of return to play postoperatively 


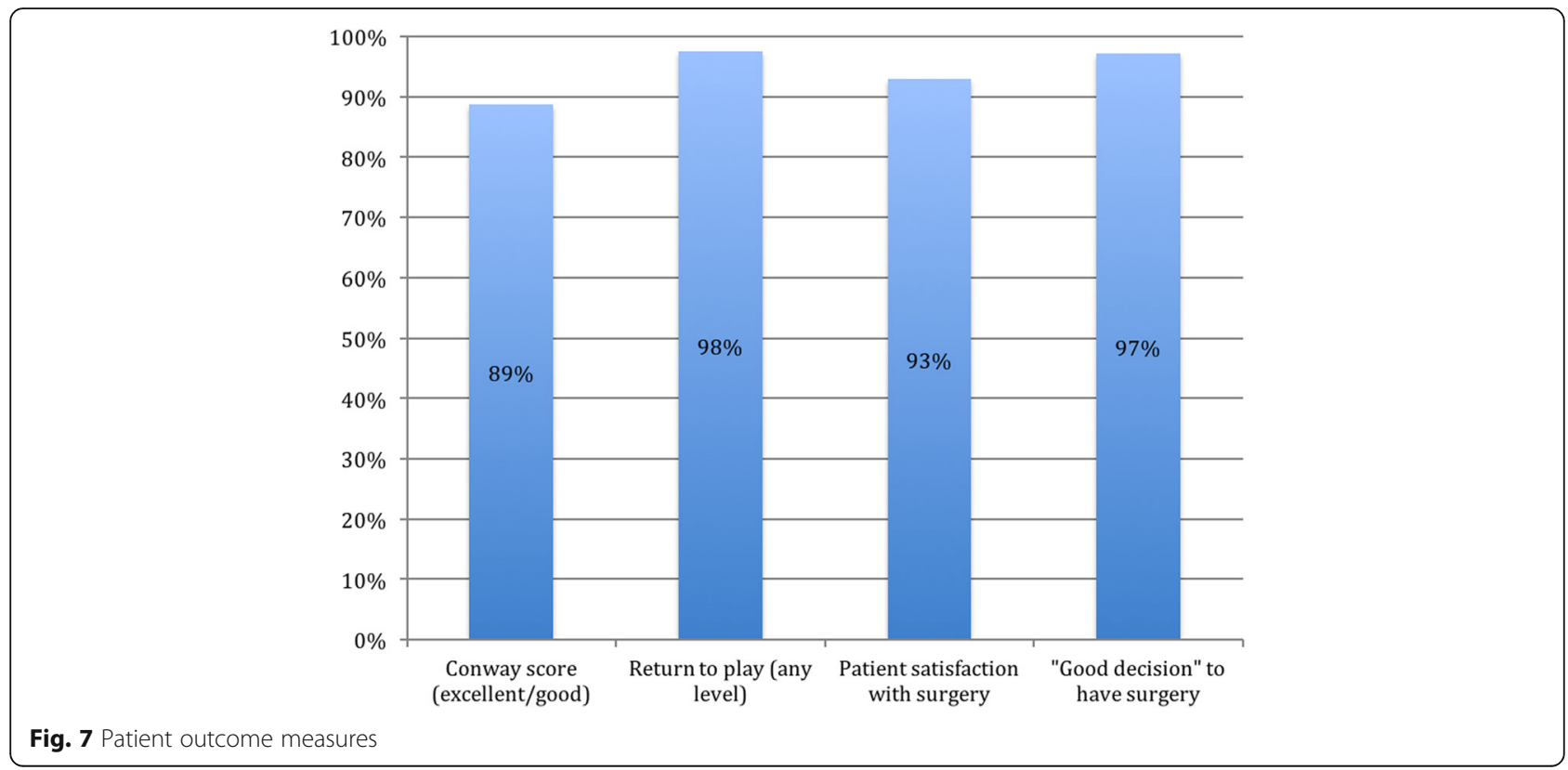

interest and ability to continue competing, these variables may change over time.

While a patient response rate of $50.1 \%$ of consecutive patients compares favorably with existing literature on UCL surgery outcomes, it is low enough to introduce significant selection bias into the results, especially those regarding patient satisfaction.

Table 1 Conway scores by study

\begin{tabular}{llll}
\hline Year & Authors & N & Excellent/Good \\
\hline 2014 & Osbahr et al. [63] & 256 & $83 \%$ \\
2013 & Jones et al. [50] & 55 & $87 \%$ \\
2013 & Savoie et al. [70] & 116 & $93 \%$ \\
2012 & Dines et al. [22] & 10 & $90 \%$ \\
2012 & Dugas et al. [29] & 120 & $90 \%$ \\
2012 & Kodde et al. [54] & 20 & $90 \%$ \\
2010 & Cain et al. [13] & 743 & $86 \%, 91 \%^{*}$ \\
2010 & Bowers et al. [10] & 21 & $100 \%$ \\
2007 & Dines et al. [21] & 22 & $86 \%$ \\
2006 & Dodson et al. [25] & 100 & $97 \%$ \\
2006 & Paletta and Wright [65] & 25 & $92 \%$ \\
2006 & Koh et al. [55] & 19 & $95 \%$ \\
2004 & Petty et al. [66] & 27 & $74 \%$ \\
2002 & Rohrbough et al. [69] & 36 & $92 \%$ \\
2001 & Thompson et al. [72] & 33 & $94 \%$ \\
2000 & Azar et al. [8] & 78 & $81 \% *$ \\
1994 & Andrews and Timmerman [4] & 9 & na \\
1992 & Conway et al. [19] & 56 & $83 \%$ \\
1986 & Jobe et al. [49] & 16 & $69 \%$ \\
\hline
\end{tabular}

\section{Conclusion}

The Docking Plus technique, performed in a private practice setting outside of the previously mentioned UCL reconstruction pioneering hospitals, produces excellent subjective (e.g., patient satisfaction) and objective (e.g., Conway score) results. Further study is warranted to see if these results can be extrapolated to other surgeons and patient populations.

\section{Abbreviations}

AROM: Active range of motion; DASH: Disabilities of the Arm Shoulder \& Hand; KJOC: Kerlan Jobe Orthopedic Clinic; MEPI: Mayo Elbow Performance Index; MLB: Major League Baseball; PROM: Passive range of motion; RTP: Return to play; UCL: Ulnar collateral ligament

\section{Acknowledgements}

Not applicable.

Funding

No financial support was received for the conduct of this study or preparation of this manuscript.

\section{Availability of Data and Materials}

Please contact author for data requests.

\section{Authors' Contributions}

DBF designed the study and did data analysis, literature review, and writing. LMG executed the data retrieval and analysis, literature review, and writing. KTE performed the surgeries being studied, helped to obtain the data, and assisted in writing and editing. All authors read and approved the final manuscript.

\section{Ethics Approval and Consent to Participate}

Our study was determined to be IRB exempt as it was an anonymous survey. ShulmanIRB \# 201607774.

Consent for Publication

No individual person's data is present. 


\section{Competing Interests}

The authors, Benjamin Donohue, Marc Lubitz, and Timothy Kremchek, declare that they have no competing interests.

\section{Publisher's Note}

Springer Nature remains neutral with regard to jurisdictional claims in published maps and institutional affiliations.

\section{Author details 45241, USA. \\ Received: 9 July 2018 Accepted: 2 December 2018 \\ Published online: 16 January 2019}

'Cayuga Medical Associates, 16 Brentwood, Suite A, Ithaca, NY 14850, USA. ${ }^{2}$ UMass Medical School, 55 Lake Ave N, Worcester, MA 01655, USA. ${ }^{3}$ Beacon Orthopeadics and Sports Medicine, 500 E Business Way, Cincinnati, $\mathrm{OH}$

\section{References}

1. Ahmad C, Grantham W, Greiwe R. Public perceptions of Tommy John surgery. Phys Sportsmed. 2012;40(2):64-72. https://doi.org/10.3810/psm. 2012.05.1966

2. Ahmad CS. Treatment of medial collateral ligament injuries of the elbow with use of the "Tommy John" operation: indications and results. JBJS Rev. 2014;2(6):1-9.

3. Aguinaldo $\mathrm{AL}$, Chambers $\mathrm{H}$. Correlation of throwing mechanics with elbow valgus load in adult baseball pitchers. Am J Sports Med. 2009;37(10):2043-8. https://doi.org/10.1177/0363546509336721.

4. Andrews JR, Timmerman LA. Outcome of elbow surgery in professional baseball players. Am J Sports Med. 1994;23(4):407-13. https://doi.org/10. 1177/036354659502300406.

5. Argo D, Trenhaile SW, Savoie FH, Field LD. Operative treatment of ulnar collateral ligament insufficiency of the elbow in female athletes. Am J Sports Med. 2006;34(3):431-7. https://doi.org/10.1177/0363546505281240.

6. Assouline J. Tommy John Surgery and Throwing 95+ MPH. http://wWw. fangraphs.com/. http://www.fangraphs.com/community/tommy-johnsurgery-and-throwing-95-mph/.

7. Atanda A, Buckley PS, Hammoud S, Cohen SB, Nazarian LN, Ciccotti MG. Early anatomic changes of the ulnar collateral ligament identified by stress ultrasound of the elbow in young professional baseball pitchers. Am J Sports Med. 2015;43(12):2943-9. https://doi.org/10.1177/0363546515605042.

8. Azar FM, Andrews JR, Wilk KE, Groh D. Operative treatment of ulnar collateral ligament injuries of the elbow in athletes. Am J Sports Med. 2000; 28(1):16-23. http://www.ncbi.n/m.nih.gov/pubmed/10653538

9. Bernas GA, Ruberte Thiele RA, Kinnaman KA, Hughes RE, Miller BS, James E. Defining safe rehabilitation for ulnar collateral ligament reconstruction. Am J Sports Med. 2009;37(12):2392-400. https://doi.org/10.1177/ 0363546509340658.

10. Bowers AL, Dines JS, Dines DM, Altchek DW. Elbow medial ulnar collateral ligament reconstruction: clinical relevance and the docking technique. J Shoulder Elb Surg. 2010;19(2 SUPPL):110-7.

11. Bruce JR, Andrews JR. Ulnar collateral ligament injuries in the throwing athlete. J Am Acad Orthop Surg. 2014;22(5):315-25. https://doi.org/10.5435/ JAAOS-22-05-315.

12. Bruce JR, Hess R, Joyner P, Andrews JR. How much valgus instability can be expected with ulnar collateral ligament (UCL) injuries? A review of 273 baseball players with UCL injuries. J Shoulder Elb Surg. 2014;23(10):1521-6. https://doi.org/10.1016/j.jse.2014.05.015.

13. Cain EL, Andrews JR, Dugas JR, et al. Outcome of ulnar collateral ligament reconstruction of the elbow in 1281 athletes: results in 743 athletes with minimum 2-year follow-up. Am J Sports Med. 2010;38(12):2426-34. https:// doi.org/10.1177/0363546510378100.

14. Chalmers PN, Erickson BJ, Ball B, Romeo AA, Verma NN. Fastball pitch velocity helps predict ulnar collateral ligament reconstruction in Major League Baseball pitchers. Am J Sports Med. 2016;44(8):2130-5. https://doi. org/10.1177/0363546516634305.

15. Chang ES, Dodson CC, Ciccotti MG. Comparison of surgical techniques for ulnar collateral ligament reconstruction in. J Am Acad Orthop Surg. 2016; 24(3):135-49.

16. Ciccotti MG, Atanda A, Nazarian LN, Dodson CC, Holmes L, Cohen SB. Stress sonography of the ulnar collateral ligament of the elbow in professional baseball pitchers: a 10-year study. Am J Sports Med. 2014;42:1-8. https://doi. org/10.1177/0363546513516592.

17. Conte SA, Fleisig GS, Dines JS, et al. Prevalence of ulnar collateral ligament surgery in professional baseball players. Am J Sports Med. 2014. https://doi. org/10.1177/0363546515580792.

18. Conte SA, Hodgins JL, NS EA, Patterson-Flynn N, Ahmad CS. Media perceptions of Tommy John surgery. Phys Sportsmed. 2015;43(4):375-80. https://doi.org/10.1080/00913847.2015.1077098.

19. Conway JE, Jobe FW, Glousman RE, Pink MM. Medial instability of the elbow in throwing athletes. J Bone Jt Surg. 1992;74(I):67-83.

20. De Smet AA, Winter TC, Best TM, Bernhardt DT. Dynamic sonography with valgus stress to assess elbow ulnar collateral ligament injury in baseball pitchers. Skelet Radiol. 2002:31(11):671-6. https://doi.org/10.1007/s00256-002-0558-0.

21. Dines JS, ElAttrache NS, Conway JE, Smith W, Ahmad CS. Clinical outcomes of the DANE TJ technique to treat ulnar collateral ligament insufficiency of the elbow. Am J Sports Med. 2007;35(12):2039-44. https://doi.org/10.1177/ 0363546507305802.

22. Dines JS, Jones KJ, Kahlenberg C, Rosenbaum a, Osbahr DC, Altchek DW. Elbow ulnar collateral ligament reconstruction in javelin throwers at a minimum 2-year follow-up. Am J Sports Med. 2012;40(1):148-51. https://doi. org/10.1177/0363546511422350.

23. Dines JS, Yocum LA, Frank JB, NS EA, Gambardella RA, Jobe FW. Revision surgery for failed elbow medial collateral ligament reconstruction. Am J Sports Med. 2008;36(6):1061-5. https://doi.org/10.1177/0363546508314796.

24. Dodson CC, Slenker N, Cohen SB, Ciccotti MG, DeLuca P. Ulnar collateral ligament injuries of the elbow in professional football quarterbacks. J Shoulder Elb Surg. 2010;19(8):1276-80. https://doi.org/10.1016/j.jse.2010.05.028.

25. Dodson CC, Thomas A, Dines JS, Nho SJ, Williams RJ, Altchek DW. Medial ulnar collateral ligament reconstruction of the elbow in throwing athletes. Am J Sports Med. 2006:34(12):1926-32. https://doi.org/10.1177/0363546506290988.

26. Domb BG, Davis JT, Alberta FG, et al. Clinical follow-up of professional baseball players undergoing ulnar collateral ligament reconstruction using the new Kerlan-Jobe orthopaedic clinic overhead athlete shoulder and elbow score (KJOC score). Am J Sports Med. 2010;38(8):1558-63. https://doi. org/10.1177/0363546509359060.

27. Donohue BF, Lubitz MG, Kremchek TE, Elbow ulnar collateral ligament reconstruction using a 4-Strand docking plus technique. Arthrosc Tech. 2017:6(4):e1201-9. https://doi.org/10.1016/j.eats.2017.04.012.

28. Douoguih WA, Dolce DL, Lincoln AE. Early cocking phase mechanics and upper extremity surgery risk in starting professional baseball pitchers. Orthop J Sport Med. 2015;3(4):1-6. https://doi.org/10.1177/2325967115581594.

29. Dugas JR, Bilotta J, Watts CD, et al. Ulnar collateral ligament reconstruction with gracilis tendon in athletes with Intraligamentous bony excision: technique and results. Am J Sports Med. 2012;40(7):1578-82. https://doi.org/ 10.1177/0363546512446927.

30. Dugas JR, Walters BL, Beason DP, et al. Biomechanical comparison of ulnar collateral ligament repair with internal bracing versus modified Jobe reconstruction. Am J Sports Med. 2016:44(3):735-41. https://doi.org/10.1177/ 0363546515620390

31. Dun S, Loftice J, Fleisig GS, Kingsley D, Andrews JR. A biomechanical comparison of youth baseball pitches: is the curveball potentially harmful? Am J Sports Med. 2008;36(4):686-92. https:/doi.org/10.1177/0363546507310074.

32. Erickson BJ, Bach BR Jr, Cohen MS, et al. Ulnar collateral ligament reconstruction the rush experience; 2014. p. 1-8. https://doi.org/10.1177/ 2325967115626876.

33. Erickson BJ, Chalmers PN, Bush-Joseph CA, Verma NN, Romeo AA. Ulnar collateral ligament reconstruction of the elbow: a systematic review of the literature. Ortho J Sport Med. 2015;3(12):1-7. https://doi.org/10.1177/ 2325967115618914.

34. Erickson BJ, Gupta a K, Harris JD, et al. Rate of return to pitching and performance after Tommy John surgery in Major League Baseball pitchers. Am J Sports Med. 2013:42(3):536-43. https://doi.org/10.1177/0363546513510890.

35. Erickson BJ, Nwachukwu BU, Rosas S, et al. Trends in medial ulnar collateral ligament reconstruction in the United States: a retrospective review of a large private-payer database from 2007 to 2011. Am J Sports Med. 2015; 43(7):1770-4. https://doi.org/10.1177/0363546515580304.

36. Eygendaal D, Olsen BS, Jensen SL, Seki A, Sojbjerg JO. Kinematics of partial and total ruptures of the medial collateral ligament of the elbow. Shoulder Elb Surg. 1999;8(6):612-6.

37. Farrow LD, Mahoney AP, Sheppard JE, Schickendantz MS, Taljanovic MS Sonographic assessment of the medial ulnar collateral ligament distal ulnar 
attachment. J Ultrasound Med. 2014;33(8):1485-90. https://doi.org/10.7863/ ultra.33.8.1485.

38. Feltner M, Dapena J. Dynamics of the shoulder and elbow joints of the throwing arm during a baseball pitch. Int J Sport Biomech. 1986;2(4):235-59. http://ci.nii.ac.jp/naid/10010918477/

39. Fleisig GS, Andrews JR, Cutter GR, et al. Risk of serious injury for young baseball pitchers: a 10-year prospective study. Am J Sports Med. 2011;39(2): 253-7. https://doi.org/10.1177/0363546510384224.

40. Fleisig GS, Andrews JR, Dillman CJ, Escamilla RF. Kinetics of baseball pitching with implications about injury mechanisms. Am J Sports Med. 1995;23(2):233-9. https://doi.org/10.1177/036354659502300218.

41. Fleisig GS, Andrews JR. Prevention of elbow injuries in youth baseball pitchers. Sport Heal A Multidiscip Approach. 2012;4(5):419-24. https://doi. org/10.1177/1941738112454828.

42. Fleisig GS, Bolt B, Fortenbaugh D, Wilk KE, Andrews JR. Biomechanical comparison of baseball pitching and long-toss: implications for training and rehabilitation. J Orthop Sports Phys Ther. 2011;41(5):296-303. https://doi. org/10.2519/jospt.2011.3568.

43. Gassko D. Have pitchers become more fragile? 2007. http://www. hardballtimes.com/have-pitchers-become-more-fragile/.

44. Gibson BW, Webner D, Huffman GR, Sennett BJ. Ulnar collateral ligament reconstruction in major league baseball pitchers. Am J Sports Med. 2007; 35(4):575-81. https://doi.org/10.1177/0363546506296737.

45. Gregory B, Nyland J. Medial elbow injury in young throwing athletes. Muscles Ligaments Tendons J. 2013;3:91-100. https://doi.org/10.11138/mlt/2013.3.2.91.

46. Hodgins UL, Vitale M, Arons RR, Ahmad CS. Epidemiology of medial ulnar collateral ligament reconstruction: a 10-year study in New York state. AJSM. 2016:44(3):729-34. https://doi.org/10.1177/0363546515622407.

47. Humphrey B. Why the MLB pitching "Win" stat is obsolete in one graph. http://www.vivaelbirdos.com/2014/1/13/5296618/why-the-stat-of-pitchingwins-is-obsolete-in-one-graph. Accessed 25 May 2016.

48. Jiang JJ, Leland JM. Analysis of pitching velocity in major league baseball players before and after ulnar collateral ligament reconstruction. Am J Sports Med. 2014;42(4):880-5. https://doi.org/10.1177/0363546513519072.

49. Jobe FW, Stark H, Lombardo SJ. Reconstruction of the ulnar collateral ligament in athletes. J Bone Joint Surg Am. 1986;68(8):1158-63.

50. Jones KJ, Conte S, Patterson N, ElAttrache NS, Dines JS. Functional outcomes following revision ulnar collateral ligament reconstruction in Major League Baseball pitchers. J Shoulder Elb Surg. 2013;22(5):642-6. https://doi.org/10.1016/j.jse.2013.01.031.

51. Jones KJ, Dines JS, Rebolledo BJ, et al. Operative management of ulnar collateral ligament insufficiency in adolescent athletes. Am J Sports Med. 2014;42(1):117-21. https://doi.org/10.1177/0363546513507695.

52. Kaplan KM, ElAttrache NS, Jobe FW, Morrey BF, Kaufman KR, Hurd WJ. Comparison of shoulder range of motion, strength, and playing time in uninjured high school baseball pitchers who reside in warm- and cold-weather climates. Am I Sports Med. 2011;39(2):320-8. https:/doi.org/10.1177/0363546510382230.

53. Keller RA, Steffes MJ, Zhuo D, Bey MJ, Moutzouros V. The effects of medial ulnar collateral ligament reconstruction on Major League pitching performance. J Shoulder Elb Surg. 2014;23(11):1591-8. https://doi.org/10.1016/j.jse.2014.06.033.

54. Kodde IF, Rahusen FTG, Eygendaal D. Long-term results after ulnar collateral ligament reconstruction of the elbow in European athletes with interference screw technique and triceps fascia autograft. J Shoulder Elb Surg. 2012;21(12):1656-63. https://doi.org/10.1016/j.jse.2012.07.010.

55. Koh JL, Schafer MF, Keuter G, Hsu JE. Ulnar collateral ligament reconstruction in elite throwing athletes. Arthrosc - J Arthrosc Relat Surg 2006;22(11):1187-91. https://doi.org/10.1016/.arthro.2006.07.024.

56. Makhni EC, Lee RW, Morrow ZS, Gualtieri AP, Gorroochurn P, Ahmad CS. Performance, return to competition, and reinjury after Tommy John surgery in Major League Baseball pitchers: a review of 147 cases. Am J Sports Med. 2014;42(6):1323-32. https://doi.org/10.1177/ 0363546514528864

57. Mcgraw MA, Kremchek TE, Hooks TR, Papangelou C. Biomechanical evaluation of the docking plus ulnar collateral ligament reconstruction technique compared with the docking technique. Am J Sports Med. 2013; 41:9-11. https://doi.org/10.1177/0363546512466375.

58. Morrey BF, An KN. Articular and ligamentous contributions to the stability of the elbow joint. Am J Sports Med. 1983;11(5):315-9. https://doi.org/10.1177/ 036354658301100506.

59. Morrey BF, An KN. Stability of the elbow: osseous constraints. J Shoulder Elb Surg. 2005;14(1 SUPPL):174-8. https://doi.org/10.1016/j.jse.2004.09.031.
60. Nazarian LN, McShane JM, Ciccotti MG, O'Kane PL, Harwood MI. Dynamic US of the anterior band of the ulnar collateral ligament of the elbow in asymptomatic major league baseball pitchers. Radiology. 2003;227(1):149-54. https://doi.org/10.1148/radiol.2271020288.

61. Nissen CW, Westwell M, Ounpuu S, Patel M, Solomito M, Tate J. A biomechanical comparison of the fastball and curveball in adolescent baseball pitchers. Am J Sports Med. 2009;37(8):1492-8. https://doi.org/10. $1177 / 0363546509333264$

62. Olsen S, Fleisig G, Dun S, Loftice J, Andrews J. Risk factors for shoulder and elbow injuries in adolesent baseball pitchers. Am J Sports Med. 2006;34(6): 905-12. https://doi.org/10.1177/0363546505284188.

63. Osbahr DC, Cain EL, Raines BT, Fortenbaugh D, Dugas JR, Andrews JR. Long-term outcomes after ulnar collateral ligament reconstruction in competitive baseball players: minimum 10-year follow-up. Am J Sports Med. 2014:42(6):1333-42. https://doi.org/10.1177/0363546514528870.

64. Osbahr D, Swaminathan S, Allen A. Combined Flexor-Pronator Mass and Ulnar Collateral Ligament Injuries in the Elbows of Older Baseball Players. AJSM. 2010.

65. G a P, Wright RW. The modified docking procedure for elbow ulnar collateral ligament reconstruction: 2-year follow-up in elite throwers. Am J Sports Med. 2006;34(10):1594-8. https://doi.org/10.1177/0363546506289884.

66. Petty DH. Ulnar collateral ligament reconstruction in high school baseball players: clinical results and injury risk factors. Am J Sports Med. 2004;32(5): 1158-64. https://doi.org/10.1177/0363546503262166.

67. Register-Mihalik JK, Oyama S, Marshall SW, Mueller FO. Pitching practices and self-reported injuries among youth baseball pitchers: a descriptive study. Athl Train Sport Heal Care. 2012;4(1):11-20. https://doi.org/10.3928/ 19425864-20110331-01.

68. Roegele J. An analysis of available Tommy John surgery data. The hardball times. 2014. http://www.hardballtimes.com/an-analysis-of-available-tommyjohn-surgery-data/.

69. Rohrbough JT, Altchek DW, Hyman J, Williams RJ, Botts JD. Medial collateral ligament reconstruction of the elbow using the docking technique. Am J Sports Med. 2002;30(4):541-8.

70. Savoie FH, Morgan C, Yaste J, Hurt J, Field L. Medial ulnar collateral ligament reconstruction using hamstring allograft in overhead throwing athletes. J Bone Jt Surg. 2013;95(12):1062-6. https://doi.org/10.2106/JBJS.L.00213.

71. Schwartz ML, al-Zahrani S, Morwessel RM, Andrews JR. Ulnar collateral ligament injury in the throwing athlete: evaluation with saline-enhanced MR arthrography. Radiology. 1995:197(1):297-9. https://doi.org/10.1148/ radiology.197.1.7568841

72. Thompson WH, Jobe FW, Yocum LA, Pink MM. Ulnar collateral ligament reconstruction in athletes: muscle-splitting approach without transposition of the ulnar nerve. J Shoulder Elb Surg. 2001;10(2):152-7. https://doi.org/10. 1067/mse.2001.112881.

73. Timmerman $L A$, Andrews JR. Undersurface tear of the ulnar collateral ligament in baseball players. A newly recognized lesion. Am J Sports Med. 2011;22(1):33-6. https://doi.org/10.1177/036354659402200106.

74. Timmerman LA, Schwartz ML, Andrews JR. Preoperative evaluation of the ulnar collateral ligament by magnetic resonance imaging and computed tomography arthrography. Am J Sport Med. 1994;22(1):26-32.

75. Werner SL, Fleisig GS, Dillman CJ, Andrews JR. Biomechanics of the elbow during baseball pitching. J Orthop Sports Phys Ther. 1993;17(6):274-8. https://doi.org/10.2519/jospt.1993.17.6.274.

76. Wood N, Konin JG, Nofsinger C. Diagnosis of an ulnar collateral ligament tear using musculoskeletal ultrasound in a collegiate baseball pitcher: a case report. N Am J Sports Phys Ther. 2010;5(4):227-33. http://www. pubmedcentral.nih.gov/articlerender.fcgi?artid=3096144\&tool= pmcentrez\&rendertype $=$ abstract

77. Youth UCL Surgery ("Tommy John surgery"). 2016. http://www.asmi.org/ research.php?page=research\&section $=\mathrm{UCL}$.

78. Zaremski IL, Horodyski M, Donlan RM, Brisbane ST, Farmer KW. Does geographic location matter on the prevalence of ulnar collateral ligament reconstruction in collegiate baseball pitchers? Orthop J Sport Med. 2015; 3(11):2325967115616582. https://doi.org/10.1177/2325967115616582.

79. Zimmerman J. Velocity's relationship with pitcher arm injuries. Hardballtimes; 2016. p. 1-18. http://www.hardballtimes.com/velocitysrelationship-with-pitcher-arm-injuries/ 